\title{
The Experiment and Numerical Simulation of Al Droplets Collision
}

\author{
WU Guanjie ${ }^{1, a,{ }^{*}}, \mathrm{HU}$ Chunbo $^{1, \mathrm{~b}}$ and WEI Xuan ${ }^{2, c}$ \\ ${ }^{1}$ Northwestern Polytechnical University, Xi'an City, 710072, China \\ ${ }^{2}$ The 210 Institute of the Sixth Academy of CASIC, Xi'an City, 710065, China \\ a309431529@qq.com, b826972533@qq.com, crenrenwv@163.com, "corresponding author
}

Keywords: 3D printing technology, molten Al, droplets collision, numerical simulation

\begin{abstract}
The molten Al (aluminum) droplets collision research was conducted to investigate the collision mechanism in high temperature field. By using the 3D printing technology, the solid Al was melted into liquid by high-frequency electromagnetic heater, and the collision process was recorded by high speed camera. Meanwhile the numerical simulation of collision was calculated by Gerris. The results show that the coalescence occurs after tiny deformation, when the $580 \mu \mathrm{m} \mathrm{Al}$ droplet has a collision with the $990 \mu \mathrm{m} \mathrm{Al}$ droplet at a relative velocity $0.89 \mathrm{~m} / \mathrm{s}$, and the new Al droplet diameter is about $1.05 \mu \mathrm{m}$. The result of simulation is also collision coalescence, which is in good accordance with the experiments.
\end{abstract}

\section{Introduction}

As a common liquid fluid flow phenomenon,the droplet collision occurs in various fields of daily life and industrial production, such as precipitation, waterfalls, and the liquid fuel atomization of aircraft engines. Al droplets collision, one of the multi-physics processes in the engine combustion, could effect the two-phrase flow and combustion stability. Therefore, it is vert significant to reveal the collision mechanism of Al droplets and establish the collision model.

The previous researchers on droplet collisions mainly studied on water droplets collision or the collision between water droplets and the water surface. Adam [1] studied the laws of the collision of two equal-sized water droplets in the air for the first time in 1968 and recorded the whole process of droplets collision. In 1992, the collision processes of five kinds of hydrocarbon fuel droplets (about $300 \mu \mathrm{m}$ in diameter) were studied by Professor C.K.Law[2-5] in Princeton University, and the results of five different droplet collisions were obtained for the first time, namely, (I) coalescence after minor deformation, (II)bouncing, (III) coalescence after substantial deformation, (IV) coalescence followed by separation for near head-on collisions and (V) coalescence followed by separation for off-center collisions. An experimental study on ethanol droplet collisions was conducted by Estrade[6] in 1999, who observed four types (II), (III), (IV), (V) of ethanol droplets collisions, and established the prediction model of droplet bouncing. The effect of droplet viscosity on the droplets collision was studied by Gotaas[7] in 2007, who summed up the experimental results of previous experiments and obtained the relationship between critical Weber number and Oh of the droplet coalescence. In 2011, Xia Shengyong[8] did the experiment of $\mathrm{Al} / \mathrm{Al}_{2} \mathrm{O}_{3}$ particles collisions, that were conducted by the solid rocket motor ignition, and he studied the effects of particle velocity, concentration and collision angle on the distribution of the particle flow before and after collision. However, the research results could hardly be applied to numerical and theoretical studies, on account of the macroscopical experimental method.

It can be seen from the above research that the experimental study on droplets collisions are mainly conducted at normal temperature, and it is difficult for the metal droplets collision in high temperature. However, 3D technology printing, as a new manufacturing technology, is likely to be a revolutionary booster for the world's manufacturing technology. Houben[9] gave a detailed description of design methods and key technologies of 3D printing equipment in his book, including the molten metal method and the jet technology for printing manufacturing. 
In this paper, the experimental method and device are established according to the idea of 3D printing technology. The molten Al droplet collision experiment is conducted by the high-frequency electromagnetic heater and the graphite crucible. The collision process of $\mathrm{Al}$ droplets is recorded by the high-speed camera, and the numerical simulation of collision are calculated by Gerris, so that the law of molten Al droplets collision in high temperature can be found.

\section{Experimental Research}

Experimental Scheme. For the research of mechanism of molten Al droplet collision, the law of two sepatate droplets collision is required primarily. The collision mechanism mainly depends on the dynamic characteristics of droplets, that include the velocity, size and cccentric distance of droplet. Therefore, the effect of these factors on droplets collision can beobtained when the Al droplet velocity and size are measured in collision.

By using the high-frequency induction heater as the heat source, the aluminum block in graphite crucible is indirectly heated and melted into the molten $\mathrm{Al}$ liquid. Then Al liquid is ejected from the nozzle, at the end of the graphite crucible, under the control of a high-frequency solenoid valve. The gas argon (Ar) come into the graphite crucible by the pneumatic drive method, and Al droplets with different size and velocity will be achieved by precise control of the solenoid valve and the mass flow rate of Ar. At last, the Al droplet collision will be obtained by high speed camera.

Experimental System. High-temperature molten droplets collision system is mainly made up of the heating system, gas supply system, cooling system, control system, acquisition system and high-temperature melting experimental device. Among them, heating system, namely, electromagnetic induction heater, is used for melting $\mathrm{Al}$ and constant liquid temperature; gas supply system mainly uses Ar, which can be used as the driving gas for the generation of droplets and the environmental protection gas droplets for the formed droplets; cooling system provides the temperature protection for some components by water cooling; control system with high-response control hardware and professional software, is mainly used to control the high-frequency solenoid valve, whose working time is very short, so that the single metal droplet can be generated; acquisition system mainly includes pressure collection, temperature acquisition and high-speed camera. The high-temperature melting experimental device includes a graphite crucible for melting metal and a closed container used for droplets collision. A transparent window is inset into the closed container for observing the molten $\mathrm{Al}$ droplet collision process. The whole experimental system is shown as follows in Figure 1, and the experimental site shown in Figure 2:

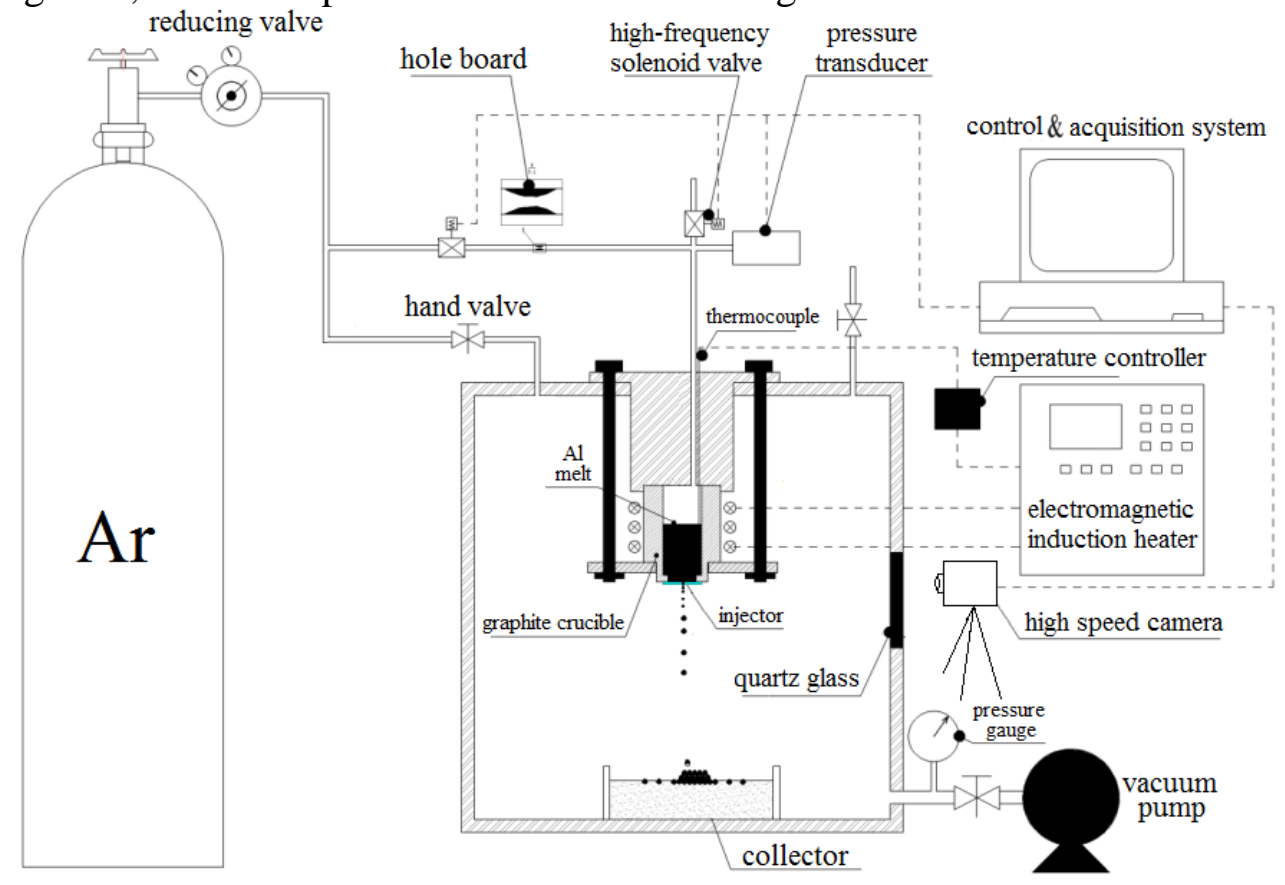

Fig.1 the system of molten Al droplets collision 


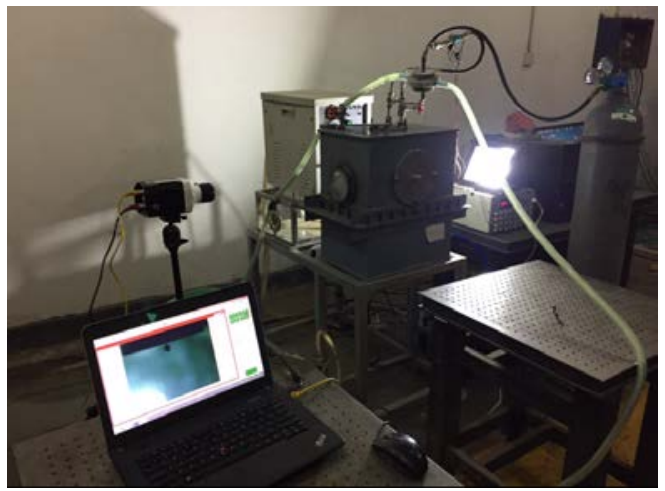

Fig. 2 the experimental site

Results and Analysis. In order to ensure the molten Al droplets can collide accurately, a single-bore graphite crucible is used to generate tiny Al droplets, making the trajectories of the Al droplets are on the same straight line. By setting the pulsed airflow, continuous Al droplets can be formed in the graphite nozzle and the minimum operating time of the high-frequency solenoid valve is $9 \mathrm{~ms}$. Due to the difference in particle size and velocity during the dropping process, these Al droplets could collide each other. The molten Al droplets collision experiment is shown as follows:

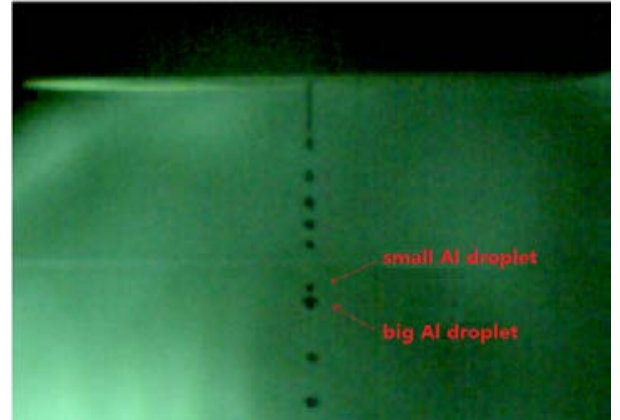

(a) before $\mathrm{Al}$ droplet collision

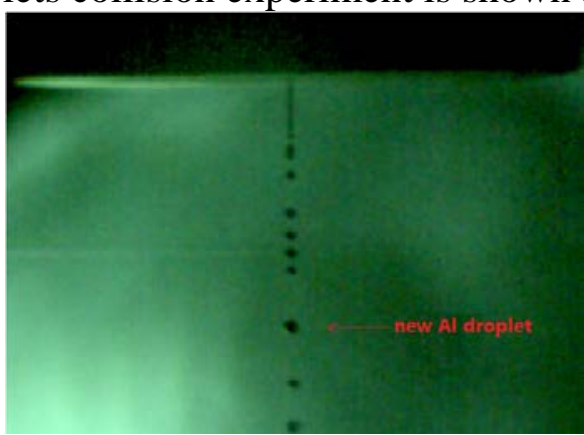

(b) after Al droplet collision

Fig. 3 the molten $\mathrm{Al}$ droplet collision experiment

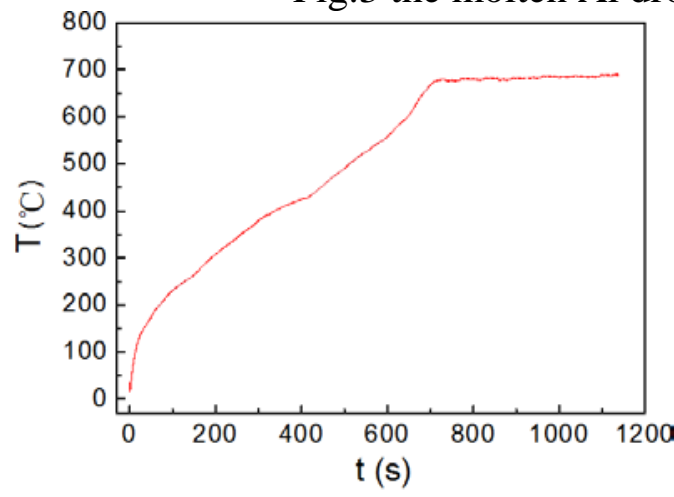

(a) "T-t” curve

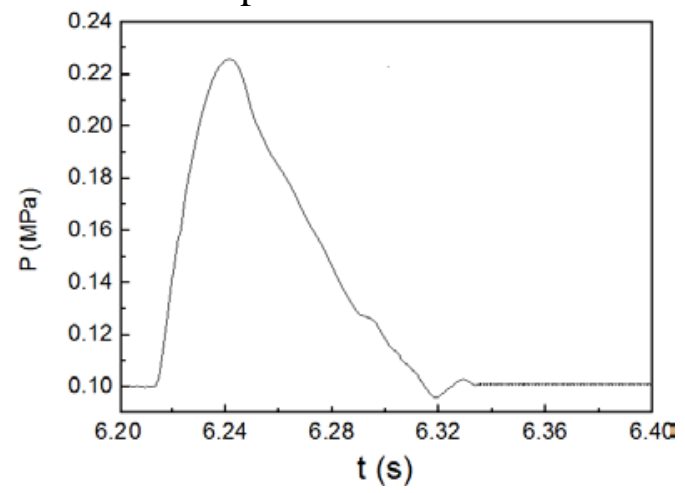

(b) "P-t" curve

Fig.4 the curves of acquistion

It can be seen from Fig. 3 and Fig.4, the small $\mathrm{Al}$ droplet collides the big $\mathrm{Al}$ droplets and then coalesce to a larger one. The $\mathrm{Al}$ in the graphite crucible was heated to a melting point of $660^{\circ} \mathrm{C}$ and stabilized at about $700^{\circ} \mathrm{C}$ by the electromagnetic induction heater. According to the pressure curve of the graphite crucible, it can be seen that with a certain amount of argon, a positive pressure can be formed inside the graphite crucible, and the melt can be extruded from the bottom of the graphite nozzle. At the top of the graphite crucible, an open outlet is set so that the gas can be emitted from it, and a transitory negative pressure environment is formed in the container. Then the melt left incompletely outflowed by the nozzle is sucked back into the crucible. The Al melt ejected from the nozzle was shattered under the action of the surface tension.

For the sake of clear images of Al droplets collision, the high-speed shooting frequency was set to 20,000 frames per second, and the image resolution was $640 \times 480$. Through enlarging the image 
during the $\mathrm{Al}$ droplets collision process, a clearer $\mathrm{Al}$ droplets collision procedure image was presented. The detail Al droplets collision process is shown below:
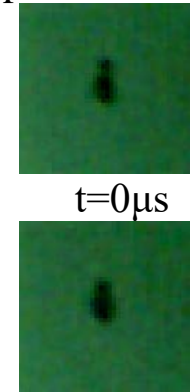

$\mathrm{t}=200 \mu \mathrm{s}$

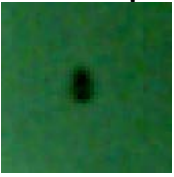

$\mathrm{t}=400 \mu \mathrm{s}$
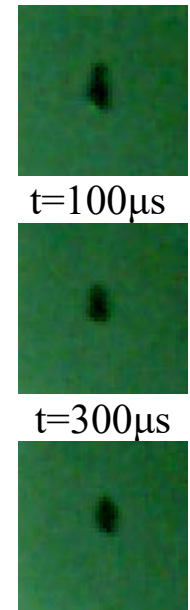

$\mathrm{t}=450 \mu \mathrm{s}$

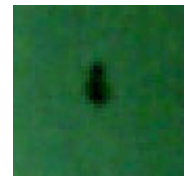

$\mathrm{t}=150 \mu \mathrm{s}$

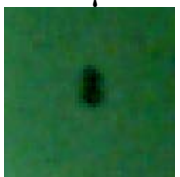

$\mathrm{t}=350 \mu \mathrm{s}$

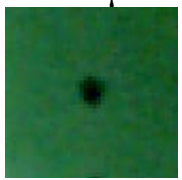

$\mathrm{t}=500 \mu \mathrm{s}$

Fig. 5 the Al droplets collision process

Al droplets collision coalescence process in Figure 5 was analyzed by the professional image processing software NI Vision Assistant. The dynamic parameters of the Al droplets before and after the collision are shown in the following table:

Table 1 the dynamic parameters of the $\mathrm{Al}$ droplets

\begin{tabular}{|c|c|c|c|}
\hline \multirow{2}{*}{ dynamic parameters } & \multicolumn{2}{|c|}{ before collision } & after collision \\
\hline & small Al droplet & big Al droplet & new Al droplet \\
\hline diam & 0.58 & 0.99 & 1.05 \\
\hline velocity (m/s) & 2.46 & 1.65 & 1.98 \\
\hline
\end{tabular}

It can be seen from Fig. 5 and Table 1, the $580 \mu \mathrm{m} \mathrm{Al}$ droplet catches up with the $990 \mu \mathrm{m} \mathrm{Al}$ droplets at a relative speed $0.89 \mathrm{~m} / \mathrm{s}$ and generates a $1.05 \mathrm{~mm}$ Al droplet. However, due to the effect of viscous force and surface tension, the whole droplet is axially stretched primarily, and then radially stretched, and last they coalesce after the deformation. The whole collision coalescence process is extremely short, only about $0.5 \mathrm{~ms}$.

\section{Numerical Simulation}

Grid Adaptation. According to the Gerris open source program[10,11], the track and reconstruction of the free interface are fulfilled by the piecewise linear VOF method. The adaptive algorithm of quadtree square grid is used in grid division to discrete space. The time domain discretization is mainly achieved by the mapping method and multi-grid numerical format. In the numerical calculation, the Al droplets and Ar property parameters are shown in Table 2.

Table 2 the property parameters of $\mathrm{Al}$ droplets and $\mathrm{Ar}$

\begin{tabular}{cccc}
\hline medium & $\rho\left(\mathrm{kg} / \mathrm{m}^{3}\right)$ & $\mu(\mathrm{Pa} \cdot \mathrm{s})$ & $\sigma(\mathrm{N} / \mathrm{m})$ \\
\hline $\mathrm{Al}$ & 2690 & $1.59 \times 10^{-3}$ & \multirow{2}{*}{0.87} \\
$\mathrm{Ar}$ & 1.78 & $2.26 \times 10^{-5}$ & \\
\hline
\end{tabular}

In the Gerris, a single GfsBox is selected as the calculation domain, whose four sides are the free flow outflow boundary conditions, and the calculation conditions are the droplet dynamics parameters before the collision, small Al droplets $(580 \mu \mathrm{m}, 2.46 \mathrm{~m} / \mathrm{s})$, big Al droplets $(990 \mu \mathrm{m}$, $1.65 \mathrm{~m} / \mathrm{s}$ ), eccentricity $\mathrm{B}=0$, and the maximum encryption level of adaptive grid $\mathrm{L}_{\max }=9$. The calculation domain grid is shown as follows: 


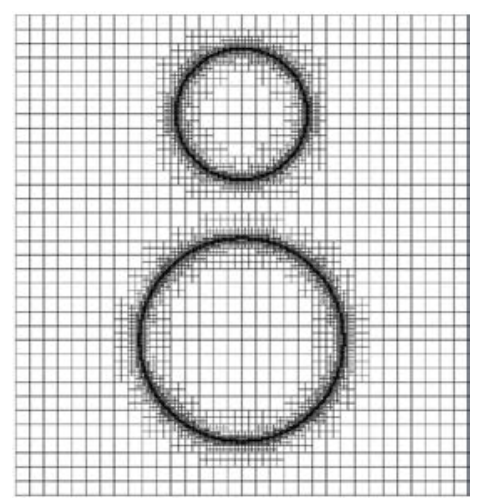

Fig.6 the adaptive grid of Al droplets

Simulation Results. The numerical simulation on the process of Al droplets collision is conducted by Gerris, and the process is calculated as follows:
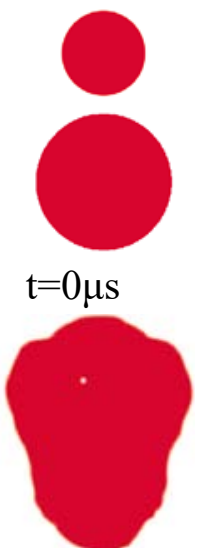

$\mathrm{t}=200 \mu \mathrm{s}$



$\mathrm{t}=320 \mu \mathrm{s}$

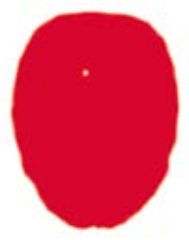

$\mathrm{t}=450 \mu \mathrm{s}$
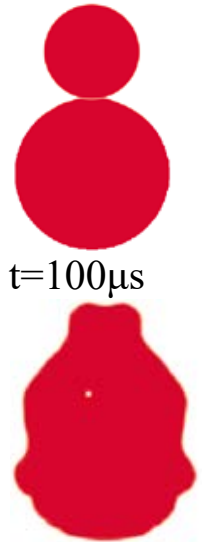

$\mathrm{t}=250 \mu \mathrm{s}$

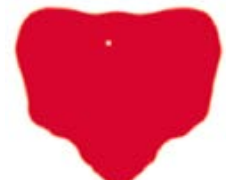

$\mathrm{t}=330 \mu \mathrm{s}$

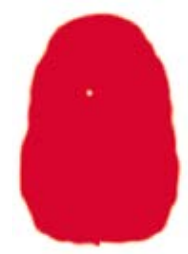

$\mathrm{t}=500 \mu \mathrm{s}$

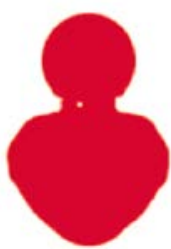

$\mathrm{t}=120 \mu \mathrm{s}$

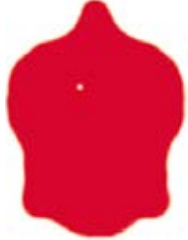

$\mathrm{t}=280 \mu \mathrm{s}$

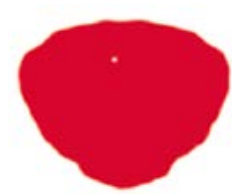

$\mathrm{t}=350 \mu \mathrm{s}$

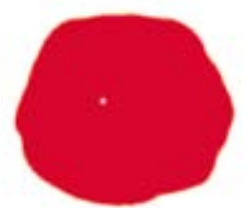

$\mathrm{t}=600 \mu \mathrm{s}$

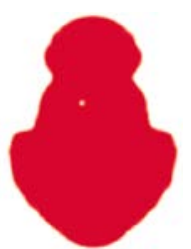

$\mathrm{t}=150 \mu \mathrm{s}$
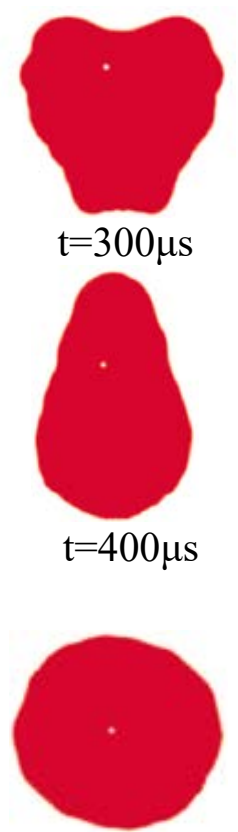

$\mathrm{t}=700 \mu \mathrm{s}$

Fig.7 the simulation of $\mathrm{Al}$ droplets collision

According to the Fig.7, small Al droplets and large Al droplets occurs coalescence after the collision, which is consistent with the results of the experiment; It takes $600 \mu \mathrm{s}$ for Al droplets from the initial collision to the final coalescence to form a single droplet, slightly longer than the experiment time of $500 \mu \mathrm{s}$. And the final $\mathrm{Al}$ droplet diameter is $1.1 \mathrm{~mm}$, which is little higher than $1.05 \mathrm{~mm}$ obtained by the experiment. It can be seen that the simulation results are in good accordance with the experimental results, which can meet the numerical calculation requirements.

The slight error of numerical calculation and experiment may be due to the bubble in the $\mathrm{Al}$ droplet. When the small $\mathrm{Al}$ droplet moves close to the large $\mathrm{Al}$ droplet, the gas between them is compressed into a thin film. At the time of reaching the minimum distance, the Van der Waals force works so that the droplets coalescence. However, due to the relatively high relative velocity between the $\mathrm{Al}$ droplets, the gas does not have enough time to flow out, and some of the gas film is wrapped in droplets in the form of bubbles.After the small droplets are coalesced with the large droplet, the 
newly formed $\mathrm{Al}$ droplet is continuously stretched and deformed, due to the residual kinetic energy of the droplets after overcoming the surface tension and the dissipation of the viscous energy. However, because the residual kinetic energy of the droplets is smaller than the surface energy of the droplets, the $\mathrm{Al}$ droplet finally becomes a more regular spherical shape.

\section{Conclusion}

By the experiment of high-temperature molten droplets collision, the relatively clear images of Al droplets collision are obtained, as is the experimental process that small Al droplet and big Al droplet generate tensile deformation and coalescence after collision. Numerical simulation is consistent with the experimental results, and the calculated data are basically in accordance with the experimental data. Therefore, the simulation can meet the calculation requirements very well.

\section{Acknowledgment}

In this paper, the research was sponsored by the National Natural Science Foundation of China (Project No. 51576166).

\section{References}

[1] Adam J. R., Lindblad N. R., and Hendricks C. D., The Collision, Coalescence, and Disruption of Water Droplets, J. Appl. Phys.11, 39 (1968) 5173-5180.

[2] Jiang Y. J., Umemura A., and Law C. K., An experiment investigation on the collision behaviour of hydrocarbon droplets, Journal of Fluid Mechanics. 234 (1992) 171-190.

[3] Qian J., and Law C. K., Regimes of coalescence and separation in droplet collision, Journal of Fluid Mechanics. 331(1997) 59-80.

[4] Wang C. H., Hung W. G., Fu S. Y., On the burning and microexplosion of collision-generated two-component droplets: miscible fuels, Combustion and Flame. 134 (2003) 289-300.

[5] Liu D., Zhang P., Law C. K., Collision dynamics and mixing of unequal-size droplets, International Journal of Heat and Mass Transfer. 57 (2013) 421-428.

[6] Estrade, J.P., Carentz, H., Lavergne, G., Experimental investigation of dynamic binary collision of ethanol droplets-a model for droplet coalescence and bouncing, International Journal of Heat and Fluid Flow. 20 (1999) 486-491.

[7] Gotaas C., Havelka P., Jakobsen H. A., Evaluation of the impact parameter in droplet-droplet collision experiments by the aliasing method, Physics of Fluids. 19(2007) 102-105.

[8] Xia S. Y., Hu C. B., Experimental Study of Collision of Liquid $\mathrm{Al}_{2} \mathrm{O}_{3} / \mathrm{Al}$ Droplets, Journal of Propulsion and Power. 29, 1 (2013) 95-103.

[9] Houben R., Equipment for printing of high viscosity liquids and molten metals, Equipment for Additive Manufacturing, The Netherlands, 2012.

[10] Information on http://gfs.sourceforge.net/wiki/index.php

[11] Khokhlov A. M., Fully threaded tree algorithms for adaptive refinement fluid dynamics simulations, Journal of Computational Physics. 143, 2 (1998) 519-543. 